\title{
A DEFINITION OF BELIEVING
}

\author{
R. G. Cronin
}

It is the aim of this paper to present a formally correct and materially adequate analysis of what it is to believe paradigmatically that $p$. The object of the analysis is believing as opposed to belief because we make a mistake if we attempt to say what belief is, independent of the believing person. There are no beliefs independent of a believing person. Any adequate analysis of belief must take the role of the person into account. The adequacy of the analysis will be tested by showing how it resolves or sheds light on certain problems having to do with belief, namely, the problem of self-deception, Pascal's wager, Moore's paradox and the notion of degrees of belief.

The thesis to be defended is that $A$ believes that $P$ if and only if $A$ is sincerely disposed to affirm that $P$ is true. Although this brief statement has the air of the trivial and philosophically uninteresting about it, the unpacking of it leads to the resolution of several important problems. The thesis has three parts, (1) the affirmation that $p$ is true, (2) the dispositional nature of believing and (3) the sincerity of the affirmation. Each part will be argued separately.

The Affirmation that $\mathrm{p}$ is True

To affirm that $p$ is to affirm that $p$ is true. The denial of this equivalence leads to an absurdity. Only a being with a concept of truth can, without equivocation, be said to have beliefs. (The problem of animal "bellefs" will be dealt with later.) A being with a concept of truth is necessarily a being with a concept of a bearer of truth and falsity, e.g. a statement, sentence, proposition, judgment, etc. That which is believed must be capable of being true or false. I cannot believe "Is the door closed?" or "Close the door!" Not being bearers of truth or falsity, these sentences are not objects of belief. Statements like "I believe Jones" or "I believe in flying saucers" do not have apparent bearers of truth or falsity as their objects, but it is clear that what is meant is "I believe what Jones says" and "I believe that flying saucers exist" in the two cases respectively. 
Exactly what we are doing in saying that something is true was spelled out by J. I. Austin. Austin's analysis of what it means to say that $p$ is true rests on six concepts: descriptive conventions, demonstrative conventions, sentences, statements, kinds of situations and actual situations. He writes

Descriptive conventions [are those] correlating words (=sentences) with types of situation, thing, event, etc., to be found in the world. Demonstrative conventions [are those] correlating the words (=statements) with historic situations, etc., to be found in the world.

A statement is said to be true when the historic state of affairs to which it is correlated by demonstrative conventions (the one to which it 'refers') is of a type with which the sentence used in making it is correlated by descriptive conventions.

In a following footnote Austin explains what he means by "is of a type."

"Is of a type with which" means "is sufficiently. like those standard states of affairs with which." Thus for a statement to be true, one state of affairs must be like certain others, which is a natural relation, but also sufficiently like to merit the same "description," which is no longer a purely natural relation. 1

In terms of Austin's analysis, to affirm that $p$ is true is to make two assertions. (1) that the actual situation a is of a certain kind or type $K$, and (2) that situations of kind $k$ are correlated by descriptive conventions with the sentence $p$. To say that the actual situation a is of kind $K$ is to say that it is sufficiently like standard cases of $\mathrm{K}-\mathrm{kind}$ situation to merit the same description. In attempting to determine the truth about some actual situation there are then two questions: (1) what we can characterize as the semantic issue, which is "What sentence is correlated with the kind of situation of which the actual situation is an instance?" and (2) what we can call the instantial issue, which is the question "Of what kind or type of situation is the actual. situation an instance?" The term "semantic issue" was chosen because it can be argued that we explain the meaning of a sentence to someone by telling him the kind of situation in (an instance of) which that sentence can be used to make a true statement. The meaning of the gentence can then be understood as being a matter of that kind of situation. A completely developed argument 
for this thesis would at present take us too far afield, but the point can be made briefly by a reductio ad absurdum argument. Imagine that a person knows the meaning of the sentence " $p$ " but does not know the kind of situation in which that sentence can be used to make a true statement. For example, the German teacher places a book on the table and asks a student, "Das Buch is auf dem Tisch, nicht wahr?" The student is unable to answer. The teacher asks if he knows what the sentence means. The student says yes. After establishing that there is nothing wrong with the student's vision, the question arises as to what other grounds there could be to say that the student does not know the meaning of the sentence. In other words, it is being argued that it cannot both be true that someone knows the meaning of a sentence and that he not know when that sentence can be used to make a true statement. If it is insisted that they can both be true the question arises, what else could serve as a sufficient reason for saying that a person does not know the meaning of the sentence.

In order to affirm that $p$ is true a person must know what the standard types or kinds of situations, things, events, etc. with which the sentence $p$ is correlated are. We make a mistake in a given situation if we attempt to settle the instantial issue before we settle the semantic issue. We cannot make the judgment that "Zeno stepped into the same river twice" is true until we settle the semantic issue, $i . e$. until we settle the question what kind of situation is going to be correlated with the sentence "A man stepped into the same river twice." This is another way of saying that we must settle the rules of our language governing the use of a sentence before we can make the judgment that those rules are being obeyed in a particular situation. The abortion controversy can be understood in light of this distinction. The question is, "Is a fetus sufficiently like a human being to merit the same description (and hence have the right to protection of the (aw)?" To be sufficiently alike to merit the same description, as Austin points out, is not a purely natural relation. The role of convention is to allow us to delineate rules for the application of sentences when the degrees of resemblance among kinds of situations is not sufficiently clear to base our distinctions on the kinds of situations themselves. The rules governing the application of a sentence to particular situations are neither true nor false. They are good or bad depending upon whether they allow us to make the distinctions we wish (find relevant) on the bases of the differences we detect.

When none of the sentences in what we might call our "sentential repertoire" is applicable without equivoca- 
tion to a particular situation, we must coin new terms or sentences (to be correlated by descriptive conventions with situations of that kind).

A person who affirms that $p$ is true $1 s$ then affirming that the actual situation (designated by some hitherto unexplained process involving demonstrative conventions) is affirming that according to the rules governing the use of the sentence " $p$ ", "p" can be used to make a true statement in this situation because the actual situation sufficiently resembles other situations (in which "p" can be used to make true statements) to merit the same
description.

\section{The Dispositional Nature of Belief}

It is not sufficient for a person to affirm that $p$ is true in order to be said to belleve it. Rather he must be disposed to do so. To illustrate, suppose that we ask Jones what he thinks about the possibility of rain. Jones proceeds to check the barometer, survey the horizon and call the Weather Service. He finds that the barometer has fallen, there are black clouds on the horlzon and the Weather Service predicts rain with a 998 probability. He then says, "Yes, I think it will rain." Imagine that minutes later Smith comes along and he asks Jones what Jones thinks about the possibility of rain. Instead of replying quite readily that he thinks it will, he goes through a process of checking the barometer, surveying the horizon and calling the Weather Service. Only then, after evaluating again the information, does he say, "Yes, I think it will." In such a case it would be erroneous to say that Jones believed that it was going to rain. Rather we should say that on two different occasions he judged that it was going to rain. Judging is episodic while belleving is dispositional. We are tempted to say that Jones believed that it was going to rain because usually the exercise of judgment resuits in the acquisition of belief. We usually acquire the disposition to affirm that $p$ is true when we make the judgment that $p$ is true. But the point of the illustration is that Jones did not have the disposition to affirm that it was true that it was going to rain. Ife had to re-judge the statement.

There is an episodic sense of the word "believe" by which we mean the acquisition of belief as in "Is that Brown?" "Yes, I believe it is." But this is a needless equivocation. We have a perfectly good word in "juage" to be used in such circumstances.

The Sincerity of the Affirmation 
It is not sufficient to be disposed to affirm that $p$ is true in order to be said to believe it. Rather there must be a sincere disposition to affirm it. The analysis of the sincerity of the disposition by far sheds the most light on the nature of belleving.

A person who wanted to decelve us about his beliefs might be disposed to affirm that $p$ is true without actually believing it. Similarly a person who is self-deceived might affirm that $p$ is true to himself and yet might still be said not to believe it. Indeed, locutions of the sort "You don't really believe that?" have meaning precisely because we can conceive of what it is for a person to affirm to himself that $p$ is true but not be sincere in doing so. The lack of sincerity is sufficient grounds for denying that he actually believes what he publicly and privately affirms. The question then becomes "Under what conditions can we judge that someone, including ourselves, is sincere in his or her affirmation that $p$ is true?"

The desire to be deceptive is one explanation of why someone would be disposed to affirm that $p$ is true when he did not in fact believe it. In seeking another explanation of why someone would be disposed to affirm that $p$ is true, we seek another end which is desired. To be deceptive is one end served by being disposed to affirm that $p$ is true. If a person is, however, sincere in his disposition to affirm that $p$ is true then there must be some other end served to explain the disposition which is characteristic of sincerity. If we consider the list of those ends which have traditionally been called ends in themselves, more often than not, knowledge is on $i t$. The desire to think as being the case that which is the case (with appropriate justification for doing sothas traditionally been one of those ends which is considered an end in itself. One cannot prove that a given end is an end itself but one can hardiy deny that knowledge has been pursued as such. In believing, we have a similar end in view. In believing, we wish to affirm to be true propositions which are in fact true with appropriate justification for doing so. The kind of justification appropriate to attaining a state of knowledge is not necessarily identical with the justification appropriate to bellef. In believing we have to settle for a second best (as $H$. H. Price puts $i^{2}$ ). We cannot be sure that we have attained the end, in this sense, of conforming our minds to reality. But that is, at least, the end we have in mind in adopting a belief in the first place.

We explain actions often in terms of citing the end served by the action. It is being argued that we explain believing in the same way, i.e. by citing the end served 
by believing. That end is, we hope, the end of conforming our minds to reality. We also explain an action by citing the prevailing circumstances which we see as evidence that undertaking that action will effect the end aimed at by the action. For example, we might explain our action of exercising by citing the end of attaining good health (an end in itself) and pointing out that exercise promotes the end of attaining good health. We explain the act of believing by pointing out the end aimed at, the conformity of mind to reality, and explain the act of assent on the basis of the evidence which we have that believing this proposition will effect the end of conforming our minds to reality. Conforming one's mind to reality can be understood as affirming of propositions which are in fact true that they are in fact true. Thus it is argued that for a person to be sincere in his disposition to affirm that $p$ is true, he must have acquired that disposition out of a desire to conform his mind to reality. The desire need not of course be conscious, not any more than we have to have the conscious desire to attain the end in itself in the execution of any action.

In contrast to the end of conforming one's mind to reality, the person who is self-deceived can be seen as adopting beliefs in the pursuit of a different end. Characteristically, a self-deceived person is one who seeks to avoid the acceptance of a proposition as true when the acceptance of that proposition will result in that person's undergoing some sort of mental suffering. The person suffering from a terminal disease who believes that he is going to recover despite overwhelming evidence to the contrary is not a person who sincerely wants to conform his mind to reality. Similarly the mother who refuses to believe that her son is guilty of some crime despite the evidence is not trying to conform her mind to reality so much as she is attempting to avoid mental. suffering. We judge that a person sincerely wishes to effect that end. The best way of conforming one's mind to reality is to believe only those propositions for which the evidence is sufficiently strong to justify discounting alternative hypotheses. How strong that evidence need be is not a question that can be addressed here. The relevant point being made here is that we have grounds for judging that we ourselves, or someone else, are self-deceived when the bellef is based upon evidence which does not meet our ordinary standards for assenting and when there is some other end served by the belief, usually the avoidance of some sort of mental suffering.

In summary then we can say that $A$ believes that $p$ if and only if $A$ is sincerely disposed to affirm that $p$ is true. A is sincere in his affirmation if and only if he 
makes his affirmation out of a desire to affirm as being true propositions which are in fact true. A person sincerely wills the end of affirming to be true propositions which are in fact true if and only if he uses the best available means for effecting that end. The best available means for effecting such an end is to adopt beliefs on the basis of the best evidence evaluated on the basis of established epistemic principles.

This definition of what believing that $p$ amounts to subsumes some but perhaps not all cases of knowledge. It is questionable whether or not one can choose not to know. Suppose I want to know the sum of a column of multi-digit figures. I add them up, check my addition, re-check via an adding machine several times and have my results checked again by another party, who has been consistently reliable and who uses the same methods. The result is always the same. At such a point I take it that a knowledge claim is justified. Suppose, however, I am a very cautious person. I am plagued by doubts that the same calculative error was made every time. I cannot sincerely affirm that it is true that this is the correct result. I cannot "close the book" on the issue in the adoption of belief. If such a case is conceivable, it would be the case that I would not believe what I can be said to know. In order to segregate belief from knowledge the definition of believing can be amended as follows: a person believes that $p$ if and only if he is sincerely disposed to affirm that $p$ is true and to acknowledge that it is compatible with all he knows that not-p. This amendment precludes one from saying that he believes statements that he knows. If a person knows that $p$ it cannot be compatible with all he knows that not-p.

It follows from the analysis of sincerity that a person who believes that $p$ in paradigm cases has good grounds for believing that $p$ but if it is compatible with all a person knows that not-p, it follows that there is a risk in believing. A theory of justification of belief is then one which would answer the question, "When despite the risk of being wrong is one justified in believing that $p$ on the basis of the available evidence?"

The foregoing theory is not a free assent theory. We are not free to believe whatever we want because we are not free to have any evidence we want. The theory is better characterized as a free "dissent" theory. We are not constrained to believe any proposition because in believing we take the risk of being wrong. Nothing can force us to take that risk. Some philosophers have taken positions incompatible with this. Anyone espousing a causal theory of belief takes the position that belief 
is caused either by having perceptions or by having sufficlent evidence that some proposition is true. To refute such theories we have only to point out that one may, like Karl Popper, eschew the entire practice of having beliefs at all. Echoing E. M. Forster, Popper says that he does not believe in belief. ${ }^{3}$ If perceptions or awareness of evidence cause belief, it follows that either Popper has no perceptions or is not aware of any evidence or he is not being candid in saying that he does not believe in belief. Popper is interested in knowledge and will not settle for a second best. Those espousing a causal theory of belief would argue that $I$ am presently constrained to believe that there is a white piece of paper now before me. If I do not know that it is a white piece of paper i.e. if there is room to doubt (e.g. it could be some substance which resembles paper) why would anyone have to ignore that doubt and assent to that proposition? If there were no room for doubt, it would be another story but if there were no room for doubt I would be logically committed to claiming to know that there is a white piece of paper now before me. If perception or having sufficient evidence were said to cause one to have inclinations to believe (as D. M. Armstrong4 says of perception), the theory would be compatible with the free dissent theory here developed.

The adequacy of this view of belief will now be tested by showing how it resolves certain problems having to do with bellef. The problem of self-deception has already been discussed.

Pascal's Wager

Pascal argues that one should believe in God in effect, because a person has the best chance of maximizing utility for himself by doing so. Assuming that those who do not believe in God will suffer the loss of heaven or worse, Pascal argues that the potential gain to be realized from believing in God far outweighs the potential gain from not believing in God. Believing in God is seen as making an investment. If God exists, believing that he does will result in infinite return on a finite investment. While if you do not believe in God and He does exist, any finite gain you may have made from the lack of belief will be far outweighed by the infinite loss. If God does not exist, you may realize a finite gain from believing that he does not (although the anxiety arising from any guilt may negate even this) and if He does not exist and you believe that He does, you may suffer a finite loss (although this may be offset by the comfort you take in your belief) but you will never know you have taken the loss. 
Given a free assent theory of belief, Pascal makes perfectly good sense. But the interesting thing about believing that God exists on the basis of possible degree of utility is that whether or not God does exist is entitely irrelvant to the fact one should believe that He does. To adopt such a belief would be to deny that one was believing for the sake of conforming one's mind to reality. We have already seen that adopting beliefs for the sake of avoiding mental anguish constitutes selfdeception. Believing that God exists on the basis of Pagcal's wager is to believe something which one does not think is true (as opposed to thinking it is not true). It is difficult to concelve of what it means to believe something when it is not the case that one thinks it is true.

\section{Moore's Paradox}

There is no contradiction in saying that $p$ is true but $A$ does not believe that $p$. There is nothing inconsistent in a proposition's being true but my not believing it. But if $I$ were to assert that $p$ is true (but $I$ do not believe that it is) I would not then be asserting a contradiction. But what would I be asserting? According to the analysis offered if $I$ gay that $I$ believe that $p I$ say that $I$ am sincerely disposed to affirm that it is true. To say that $p$ is true but $I$ do not believe it is to say that $p$ is true but $I$ am not disposed to affirm that $p$ is true. In affirming that $p$ is true I am doing what $I$ am denying $I$ am disposed to do. It cannot both be true that $I$ affirm that $p$ is true and that I am not disposed to affirm that it is. In this sense, Moore's paradox is really a contradiction. It is like saying "I never say anything."

\section{Degrees of Belief}

If the foregoing analysis is correct, it follows that there is no such thing as degrees of belief. Either a person is disposed to affirm that $p$ is true or he is not. There is no question of degree in this. What does admit of degree is the amount of evidence a person had in support of his belief and the amount of evidence which would be required for a person to alter his belief. In cases of rational belief the strength of evidence which is required to alter a belief is proportional to the strength of evidence in support of it. $A$ weakly held belief is one for which $I$ have only a modicum of evidence and for which I would only require a little evidence to change. A strongly held belief is one for which I have a great deal of evidence and require strong evidence to change. A strongly held irrational belief is one which I might not alter no matter what the 
evidence, i.e. one wherein the amount of evidence required to alter the bellef is not proportional to the amount of evidence in favor of it. The only thing which admits of degree is the strength of evidence required for revision and this is what is referred to by "degree of belief."

Pize Problem of Linguistic Inadequacy

We can attach some sense of the word "believe" to cases wherein the alleged believer does not possess the ability to formulate his belief in words. We can make some sense of someone's saying, "My cat's behavior indicates to me that he believes that he is about to be fed." But would such a person say "My cat's behavior indicates to me that he believes that it is true that he is about to be fed." The reticence a person would have about talking in this way reflects the association one must make between beliefs and objects of belief as bearers of truth and falsity. Do cats have objects of belief which are bearers of truth and falsity? If so, what are they? We have to grant that animals can make judgments with respect to the instantial issue, i.e. they can judge that a particular situation is of a certain kind. The cat might be said to be judging the present circumstances to be sufficiently like past circumstances wherin he was fed to merit the same behavior. Indeed tests of animal intelligence rely on the assumption that animals can learn to judge particular situations to be of certain kinds, e.g. the animal learns always to choose the right hand side of a T-maze in order to get food. But to insist that such behavior is logically adequate for the ascription of belief is quite another matter. Granted, with beings possessing linguistic ability, behavior is usually indicative of belief. This is because people usually act in accordance with their beliefs. And when there is a discrepency between a person's avowed beliefs and his behavior, we usually take his behavior to be more indicative of his sincere beliefs than what he says. But it is conceivable that there be a discrepency between a person's rational belief and his irrational behavior (irrational by virtue of the fact that it. is incompatible with his rational belief). To say that a person's beahvior is logically adequate for the ascription of belief, is to deny that it is possible for a person to act irrationally. Further we often act on propositions which we do not believe but to which we attach a high probability. The gambler can make reasonable bets on the probabilities of certain alternatives but refrain from adopting any beliefs about what the actual results will be, e.g. as in betting on a horse. 
One may even act on propositions which are believed to be false. A doctor may operate on a patient to save the latter's ilfe even though he believes the patient will die anyway. In such a case the degree of utility which may possibly be realized justifies the action and not the probability of success.

University of Kansas

NOTES

${ }^{1}$ J. L. Austin, "Truth," proceedings of the Aristotelian Society, Supplementary Vol. $\overline{x x i} \bar{v}(1950)$, p. 116 .

2H. H. Price, Belief. (London: George Allen and Unwin Ltd. , 1969), p. 72.

${ }^{3}$ Karl Popper, Objective Knowledge (Oxford: Oxford University Press, 1974), p. 25 .

4. M. Armstrong, Perception and the Physical World (London: Rutledge and Kegan PauI, 196I), p. 105 ff. 